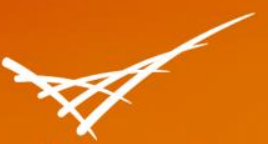

Pacific Northwest

NATIONAL LABORATORY

\title{
Meeting Summary of Kitchen Cabinet on Financial Due Diligence to Reduce Proliferation Risks
}

\section{July 2016}

G Hund

GA Carr

RA Weise 


\title{
DISCLAIMER
}

This report was prepared as an account of work sponsored by an agency of the United States Government. Neither the United States Government nor any agency thereof, nor Battelle Memorial Institute, nor any of their employees, makes any warranty, express or implied, or assumes any legal liability or responsibility for the accuracy, completeness, or usefulness of any information, apparatus, product, or process disclosed, or represents that its use would not infringe privately owned rights. Reference herein to any specific commercial product, process, or service by trade name, trademark, manufacturer, or otherwise does not necessarily constitute or imply its endorsement, recommendation, or favoring by the United States Government or any agency thereof, or Battelle Memorial Institute. The views and opinions of authors expressed herein do not necessarily state or reflect those of the United States Government or any agency thereof.

\author{
PACIFIC NORTHWEST NATIONAL LABORATORY \\ operated by \\ BATTELLE \\ for the \\ UNITED STATES DEPARTMENT OF ENERGY \\ under Contract DE-AC05-76RL01830
}

Printed in the United States of America
Available to DOE and DOE contractors from the Office of Scientific and Technical Information, P.O. Box 62, Oak Ridge, TN 37831-0062; ph: (865) 576-8401 fax: $(865) 576-5728$
email: reports $a$ adonis.osti.gov
Available to the public from the National Technical Information Service 5301 Shawnee Rd., Alexandria, VA 22312 ph: (800) 553-NTIS (6847) email: orders@ntis.gov <http://www.ntis.gov/about/form.aspx> Online ordering: http://www.ntis.gov




\section{Meeting Summary of Kitchen Cabinet on Financial Due Diligence to Reduce Proliferation Risks}

Summary

July 2016

G Hund

GA Carr

RA Weise

Prepared for

the U.S. Department of Energy

under Contract DE-AC05-76RL01830

Pacific Northwest National Laboratory

Richland, Washington 99352 



\section{Contents}

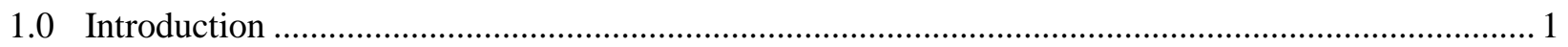

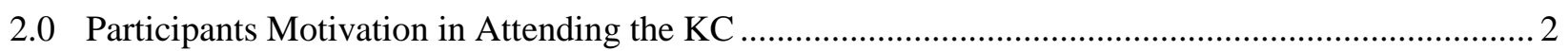

3.0 Discussion 1: Financial Institutions and Export Control Regimes ................................................. 2

4.0 Panel 1: Proliferation from Government's Perspective ............................................................... 3

5.0 Panel 2: Proliferation from Financial Institutions' Perspective ............................................................. 4

6.0 Discussion 2: Proliferation Red Flags ..................................................................................... 5

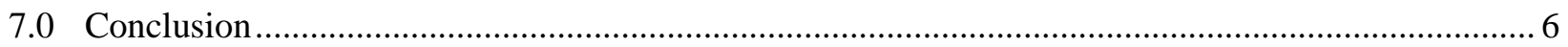





\subsection{Introduction}

The U.S. Department of Energy's Pacific Northwest National Laboratory convened the Kitchen Cabinet (KC) on April 27 $7^{\text {th }}$ 2016, to facilitate a candid discussion about the role of financial institutions (FIs) in antiproliferation efforts to reduce nuclear proliferation risks by identifying suspicious business transactions and exports when making lending or insurance decisions. The meeting brought together a group of export control specialists, largely representatives from the Nuclear Suppliers Group (NSG) Participating Governments (PGs) and finance experts representing banks and insurance companies. By assembling a $\mathrm{KC}$ of experts, the group could understand what suspicious transactions look like from each other's perspectives and better inform each of their operations. The goal was to develop red flags FIs could use to identify suspicious proliferation-related transactions and to help governments gain a clearer picture of proliferation using financial information.

This meeting was conducted under Chatham House Rules. ${ }^{1}$ Key points from the meeting are summarized below followed by a detailed summary in the next section:

- Export control and proliferation finance share common ground: the financial arrangements supporting the export of nuclear and dual-use items. Better information sharing is needed between governments and financial entities, and between a government's agencies, to help each fully understand what proliferation procurement looks like.

- Allowing proliferation experts from trade or commerce agencies access to suspicious transaction reports (STRs) could improve information sharing; export-licensing agencies could use financial information in evaluating suspicious export license applications.

- Proliferation experts and financial experts could review and dissect proliferation case studies together to create fingerprints of what proliferation looks like from the financial side; this would reduce the "language barrier" between finance and export control.

- It is not necessary to create new financial oversight bodies to look for proliferation activities in finance; existing agencies can be leveraged to reduce regulatory burden.

- Governments could consider developing outreach activities to engage FIs on proliferation risks, encouraging "risk management" instead of "compliance management."

- Governments could reward entities with integrity and avoid penalizing companies that demonstrate attempts to do the right thing.

- Governments could consider offering more guidance to finance and private industry on how to comply while conducting business, rather than just saying what companies cannot do.

- The NSG could suggest PGs develop requirements that insurance companies check for export licenses before insuring transshipments. In addition, the NSG could try to develop a multilateral mechanism to share information about insurance denials.

\footnotetext{
${ }^{1}$ Under Chatham House Rules, meeting participants are free to use the information discussed, but the identity and affiliation of the participants may not be revealed.
} 


\subsection{Participants Motivation in Attending the KC}

One government participant felt that the $\mathrm{KC}$ was important because approaches to nonproliferation must be as dynamic as evolving proliferation threats. The participant wanted to see how the NSG as an institution could respond to new proliferation challenges by focusing on opening channels of dialogue with institutions such as the Financial Action Task Force (FATF) ${ }^{1}$ to combat the undefined problem of "proliferation financing."

Additionally, participants felt the KC could be helpful in establishing regular channels of communication between the NSG and finance, which is crucial for successful nonproliferation efforts. If the NSG presented a rationale for PG involvement in proliferation finance, PGs would see more value in outreach to FIs.

Participants indicated that the meeting was important because:

- FIs could help identify previously unacknowledged patterns in proliferation and trafficking.

- The KC could promote information sharing between government agencies and private actors.

- Identifying risk information from financial transactions could help promote "risk management," possibly including a list of "green flags" that would help companies better conduct their business. This also would help insurance companies, which currently have no clear channel to share information with government.

- While Anti-Money Laundering (AML) and trafficking prevention efforts are under way, more needs to be done regarding proliferation financing. The difficulty will be balancing the needs of governments to protect confidential information with the need to share information with FIs, and addressing resistance of some countries to blurring the lines between export control regimes and FATF.

Two group discussions and two panel-led discussions were held following the remarks.

\subsection{Discussion 1: Financial Institutions and Export Control Regimes}

The discussion began with one of the hosts presenting a model showing how banks, insurers, regulators, and companies view different pieces of information in export transactions, which illustrated where information sharing could be beneficial in reducing proliferation risks. Proliferation transactions look different to different companies, governments, and agencies, so unless different entities can share information about what it sees in a given transaction, it is difficult to identify the proliferation.

A finance representative said that insurance companies with suspicious clients do not want these clients to simply walk away - they want to work with those clients to reduce risks if possible; larger banks, conversely, are less concerned if they lose some clients. Participants generally agreed that companies need more emphasis and training on risk management, as opposed to compliance management.

Another attendee pointed out that shipping companies and freight forwarders appear to be overlooked. Neither forwarders nor insurance companies really know what is in a shipping container. However, in a

${ }^{1}$ FATF. http://www.fatf-gafi.org/about/whoweare/\#d.en.11232 
perfect system, there would be a way to identify riskier freight customers so the Customs and Border Patrol would know to look in their shipping containers more closely.

An attendee added that whereas FIs have Section 314(B) of the USA PATRIOT Act, ${ }^{1}$ which provides a safe harbor for companies to report suspicious activity, freight forwarders do not. Creating liability protection, akin to that found in 314(B) and the defining reporting channels for freight forwarders and insurers, would encourage information sharing, hopefully helping to bring antiproliferation measures into corporate culture.

A participant questioned whether it would be possible to work with data vendors, such as WorldCheck ${ }^{2}$ or Factivia, to get them to include proliferation risks, which is not currently happening. Banks are legally required to search for entities on the Specially Designated Nationals Lists ${ }^{3}$, and the proactive ones are automating those checks as much as possible; however, banks are still not well equipped to evaluate proliferation risks. While banks can identify activities that look suspicious, they are unable to tell whether that suspicious activity relates to proliferation, money laundering, drug trafficking, or other illegal activities. Moreover, working with data vendors to gather public information related to proliferation could expose FIs to liability if they get the information wrong.

Another participant asked about the feasibility of adjusting the price for financial or insurance products based on proliferation risk. A financial representative explained banks find it easier not to do business with bad actors than to charge different prices for risk for two reasons: 1) laws against variable pricing prevent such pricing models, and 2) such risks could not meet the standards of legally required stress tests that banks must run before adopting new pricing models because proliferation risks are relatively nebulous and insufficiently quantified, at least at this time. Insurance companies, in contrast, could charge higher prices not for higher risks but for the more extensive due diligence required when companies have not perfected their internal compliance procedures. A finance representative explained for high-risk clients, underwriters must already add incremental costs; this structure could enable insurers to raise prices for high-proliferation-risk customers or reward extra-compliant customers with lower rates.

\subsection{Panel 1: Proliferation from Government's Perspective}

The panel opened with a description of the NSG's history of adapting to changes in proliferation strategies, with Iraq's pre-Gulf War nuclear weapons program cited as the origin of the dual-use lists. The representative added that the popularity of certain financial tools has changed over time: letters of credit have given way to open accounts, which are more difficult to monitor. Meanwhile, the Khan network used a network of banks, but as people were not looking closely at financial relationships then, his insurance arrangements are still unknown. While the physical nature of cargo shipments remains relatively unchanged, banking and communications supporting such shipments have changed significantly. Proliferators also create numerous new cover companies to do their various procurement activities. ${ }^{4}$

\footnotetext{
${ }^{1}$ Uniting and Strengthening America by Providing Appropriate Tools Required to Intercept and Obstruct Terrorism Act

2 “KYC, AML, CFT and PEP Due Diligence.” Thomson Reuters. https://risk.thomsonreuters.com/products/worldcheck

${ }^{3}$ https://www.treasury.gov/resource-center/sanctions/SDN-List/Pages/default.aspx

${ }^{4}$ See http://www.state.gov/r/pa/prs/ps/2013/218637.htm https://www.treasury.gov/press-center/press-releases/Pages/j11968.aspx
} 
A finance representative noted that while insurance companies will not insure companies on sanctions lists, if one of those entities seeks insurance but is denied, there is no mechanism for the company to report that information to governments. In contrast, banks file STRs ${ }^{1}$ when they deny a deal based on links to national or international sanctions. Without such a mechanism for insurers, information is lost.

This, coupled with a lack of positive guidance from governments, has left many private enterprises feeling helpless regarding proliferation, one attendee reported. A few solutions were proposed, one being that the NSG could suggest PGs develop requirements that insurers check for export licenses before insuring transshipments. Another proposal was the development of a multilateral mechanism to share information about finance and insurance denials to help prevent jurisdiction shopping; one suggested that if a neutral third party was used to scrub and disseminate the information, it might help alleviated countries' confidentiality concerns. A third proposal was that within a government export-licensing agencies could see STRs that are usually only reviewed by finance and justice agencies. France and the United Kingdom have mechanisms for insurance companies to share denial information with governments, but the United States does not.

\subsection{Panel 2: Proliferation from Financial Institutions' Perspective}

Participants began discussing the difference between money laundering and proliferation finance. While money laundering only occurs after a crime has been committed to hide the proceeds of that crime, proliferation financing can happen either before or after a crime has been committed. Proliferation financing can involve either facilitating an illegal transaction (which is akin to money laundering) or a legitimate transaction that ends up supporting illegal activities (which is harder to identify because no crime has occurred yet).

A finance representative noted that banks have repeatedly requested lists or proliferation typologies from governments, the development of such typologies usually falling to financial intelligence units (FIUs). Because FIUs are more interested in AML efforts, their typologies are tailored to AML, not proliferation. Unfortunately, many participants felt that FATF typologies are too vague to be useful. This lack of guidance is problematic because FIs cannot identify proliferation risks on their own.

Additionally, without guidance from government on how to comply (as opposed to regulations on what not to do), it is easier for banks to make compliance a box-checking exercise, rather than an active effort to control and reduce various risks.

Moreover, lack of guidance relating to proliferation risks can have unintended consequences if FIs tackle the problems too aggressively. For example, when banks excessively de-risk not only does it hurt communities lacking sufficient banking access, but illegal commerce is forced underground, reducing monitoring and detection of such activities. Another unintended consequence is called "defensive filing" in which banks file STRs about everything without properly managing those risks, and overwhelm government agencies.

Another finance representative noted that while banks can look at suspicious activities or money laundering, they cannot easily determine criminal activity to which the suspicious behavior is related (drugs, terrorism, proliferation, etc.). Proliferation experts can help banks identify specific indicators and

\footnotetext{
${ }^{1}$ In the United States, these reports are called "Suspicious Activity Reports" or "SARs", known in other jurisdictions as "Suspicious Transaction Reports" or "STRs." Both were discussed during the KC.
} 
"fingerprints," so as to help separate signal from the noise. To create such fingerprints, the representative listed several key questions:

1. What type of activity are we looking for?

2. Where does the fingerprint become evident in a business process?

3. What types of controls can detect such transactions?

4. To whom would that information be reported, and once reported, will export and proliferation experts have access to the information and be able to use it? ${ }^{1}$

The discussion then switched to insurance, when an attendee explained that maritime insurance might be the most relevant insurance for proliferation concerns. The attendee noted that there are three main types of maritime insurance: 1) cargo insurance that insures on the goods being shipped, 2) hull insurance that insures the vessel itself (be it a boat, car, train, etc.), and 3) liability insurance that insures the vessel owner of related damages (for example, damages resulting if the ship crashes into the port). Information about the ship or cargo being insured comes directly from the customer and cannot be independently verified in its entirety. This attendee felt maritime insurance information is where proliferation activities are most likely to appear. The attendee further explained that nearly all insurance companies use brokers to sell their insurance and brokers who are in direct contact with the customer have the best information. However, information available to brokers is not always shared with the insurance companies, so outreach to brokers is likely necessary.

Another representative added that often governments assume FIs know what to look for when conducting their know-your-customer (KYC) requirements, but that this is not always the case. More guidance from governments is required to identify proliferation-related activity through existing due diligence activities. They added that the Egmont Group, ${ }^{2}$ a group of FIUs, collects information and shares it amongst its member states. Were this information shared with export-licensing agencies, it may improve identification of typologies of financial activities related to nuclear and dual-use items. Regardless of the information-sharing mechanism adopted, privacy and liability concerns associated with information sharing will continue to be challenging.

\subsection{Discussion 2: Proliferation Red Flags}

The meeting then turned to the challenge of defining new, actionable red flags, as current red flags are either too vague or, frustratingly, too specific. A participant noted that FATF and Egmont usually generate guidance or standards, which result in the less desirable "compliance management;" actionable red flags would be far more useful.

For marine cargo insurance, unusual deal structures are red flags. While it is common for ownership of cargo on a boat or of the boat itself to change frequently, the overall deal structure must make sense.

For FIs, due diligence of existing and new customers to identify anomalies would be useful. However, identifying odd behavior for new customers is challenging because there is a limited history of

\footnotetext{
${ }^{1}$ Currently, FIs file millions of STRs annually; Law Enforcement uses these to prosecute cases as they see fit. At present, information sharing across intergovernmental agencies is ad hoc.

2 "The Egmont Group of Financial Intelligence Units." U.S. Department of the Treasury.

https://www.fincen.gov/international/egmont/
} 
transactions with customers. That customer history is usually what serves as the baseline for banks to monitor for odd or changing behavior.

Another finance representative suggested that it would be helpful if banks could see redacted proliferation case studies to help compliance officers identify suspicious activity. A government representative thought this would be possible and that seeing the proliferation activity through the finance lens would be valuable.

A finance representative suggested FIs could benefit from access to denial information from the NSG Information-Sharing System, but government representatives did not think such access was likely to be forthcoming. ${ }^{1}$

\subsection{Conclusion}

Throughout the panels and discussions, several recurring themes emerged:

- Transparency and information sharing are vital to successful nonproliferation efforts, as are welldefined communications channels to share information. FIs must know to whom they should report suspicious activity.

- Interagency information sharing, particularly giving export control agencies access to STRs, could help governments in identifying proliferation trends.

- Companies need to develop a culture of nonproliferation, with an emphasis on risk management, as opposed to compliance management.

- Government and FIs should cooperate, including jointly reviewing redacted proliferation case studies to start defining proliferation finance typologies.

- Companies crave additional proliferation finance guidance from governments, including "green flags" that would help a company know a transaction carried less risk.

- There is no need to create new financial oversight entities to look for proliferation. Leverage the existing organizations who receive STRs to help disseminate that information to export licensing and proliferation enforcement agencies, reducing the confusing reporting requirements facing FIs already.

\footnotetext{
${ }^{1}$ Currently only available to NSG PGs.
} 



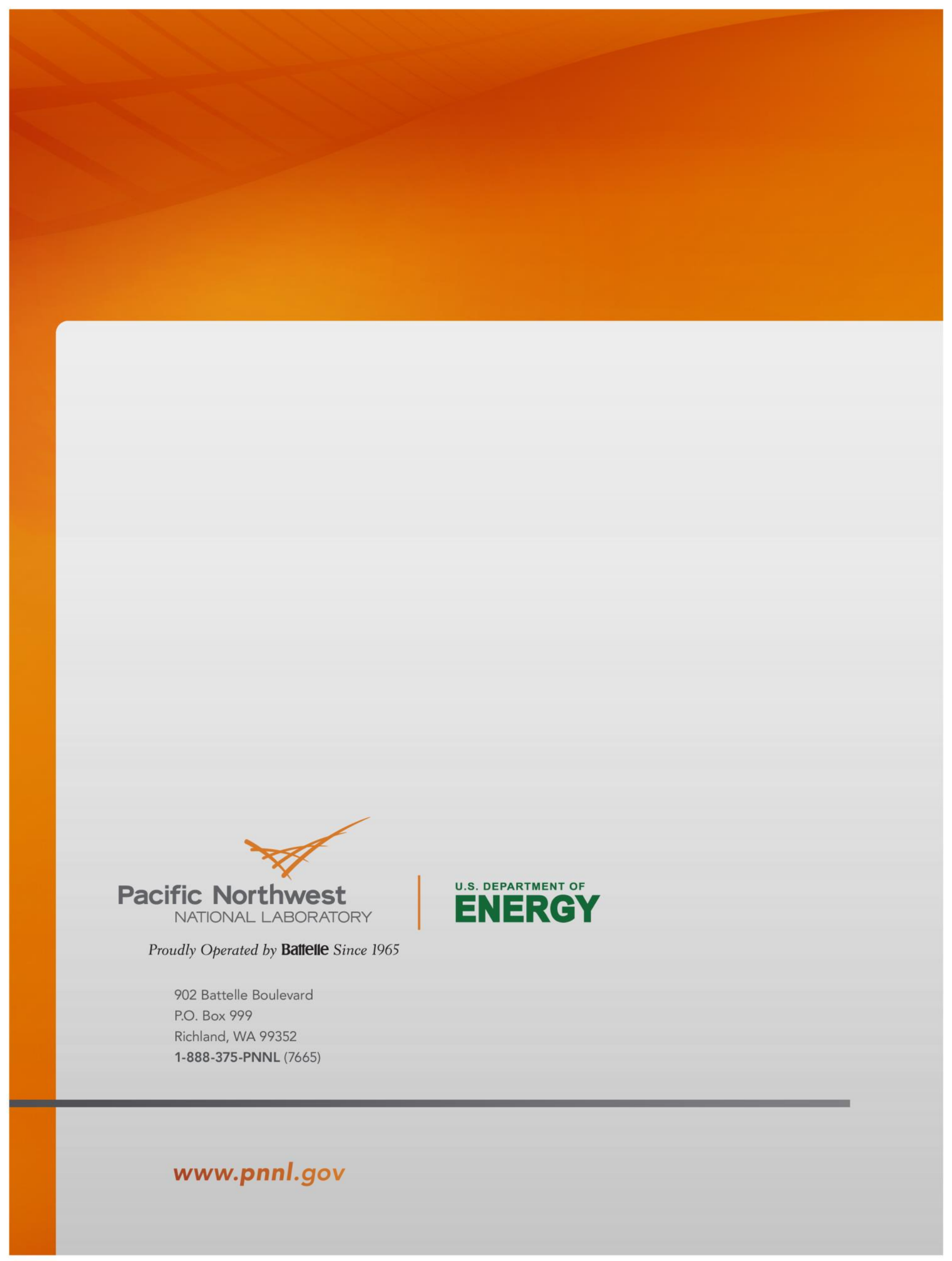

